\title{
Imigração, ocupação e logística: o Nordeste do Estado de Mato Grosso
}

\author{
João Augusto Dunck Dalosto ${ }^{1}$ \\ Cássius Dunck Dalosto² \\ Antônio Pasqualetto ${ }^{3}$ \\ Leonardo Guerra de Rezende Guedes ${ }^{4}$
}

\begin{abstract}
Resumo
O presente artigo visa analisar os efeitos da infraestrutura de transporte, em especial da BR-158, no processo de ocupação das terras e no processo de desenvolvimento econômico da Mesorregião Nordeste de Mato Grosso. Foram analisados os efeitos de investimentos em transporte em diferentes contextos de inserção, aspectos históricos regionais e coleta de dados de indicadores econômicos e fundiários, no qual foi possível quantificar e verificar a distribuição das variáveis no espaço. As conclusões apontam que a BR158 foi fator estruturador do espaço geoeconômico da região, visto que influenciou diretamente na produção agropecuária. Verificou-se, ainda, que os pequenos produtores rurais são mais dependentes de uma infraestrutura de transporte adequada e que, no geral, necessitam de apoio estatal para manter uma produção agrícola em escala comercial.
\end{abstract}

Palavras-chave: Colonização. Desenvolvimento Regional. Infraestrutura de Transporte.

\begin{abstract}
The purpose of this article is to analyze the effects of transport infrastructure, especially the BR-158, in the process of land occupation and in the process of economic development of the Northeastern Meso-region of Mato Grosso. The effects of investments in transportation in different contexts of insertion, regional historical aspects and data collection of economic and land indicators were analyzed, in which it was possible to quantify and verify the distribution of the variables in the space. The conclusions indicate that the BR-158 was a structural factor of the region's geo-economic space, since it directly influenced agricultural production. It was also found that small rural producers are more dependent on adequate transport infrastructure and that, in general, they need state support to maintain agricultural production on a commercial scale.
\end{abstract}

Keywords: Colonization. Regional Development. Transportation infrastructure.

\footnotetext{
${ }^{1}$ Mestre em Desenvolvimento e Planejamento Territorial (PUC-Goiás). Professor da Universidade do Estado de Mato Grosso (UNEMAT). dunckdalosto@gmail.com

${ }^{2}$ Mestre em Direito Agrário (UFG). Professor da Universidade Estadual de Goiás (UEG). cdalosto@gmail.com

${ }^{3}$ Professor do Programa de Pós-Graduação em Desenvolvimento e Planejamento Territorial e do Programa de PósGraduação em Engenharia de Produção e Sistemas, da Pontifícia Universidade Católica de Goiás (PUC-Goiás). profpasqualetto@gmail.com

4 Professor do Programa de Pós-Graduação em Desenvolvimento e Planejamento Territorial da Pontifícia Universidade Católica de Goiás (PUC-Goiás).prof.leonardo.guedes@gmail.com
} 


\section{Introdução}

A região nordeste de Mato Grosso, ou Mesorregião Nordeste do Estado de Mato, Brasil, foi palco de fortes intervenções estatais entre o período entre 1890 e 1980. A primeira intervenção experimentada se deu por meio da construção da Linha Telegráfica Cuiabá-Araguaia, em 1890, conjuntamente com a criação da estrada estratégica que ligava a capital do estado, Cuiabá (BRASIL, 2003). A segunda, pela atuação da Expedição Roncador-Xingu e da Fundação Brasil Central, constituindo a Marcha para o Oeste (1943-1967), a qual estabeleceu base às margens do Araguaia e de lá teceu a penetração com estradas, bases da Força Aérea Brasileira (FAB) e núcleos de povoamento (VARJÃO, 1989).

Em 1953, dez anos depois de iniciada a expedição Roncador-Xingu, os interesses econômicos se intensificaram na Mesorregião Nordeste de Mato Grosso. Programas governamentais foram criados no sentido de incentivar a consolidação populacional e ao desenvolvimento de atividades produtivas (BORGES, 1987). Notadamente, o aumento efetivo da atividade produtiva se deu na década de 1970 e 1980, período no qual houve intensa imigração de colonos da região Sul do país (SCHWANTES, 2008). Em todos esses períodos, o transporte foi tratado como peça fundamental para atingir os objetivos das políticas de desbravamento e ocupação.

Isto posto, conjuntamente no cenário nacional brasileiro, a infraestrutura de transporte se enraizou na retórica do discurso político e se consolidou nas diretrizes de ordenamento territorial, vinculada ao argumento de gerar desenvolvimento nas regiões em que atravessam. Entretanto, mostra-se importante indagar: o investimento em infraestrutura de transporte pode ser considerado um fator estruturador do território? Na bibliografia relacionada à temática, ficam evidentes que obras de infraestrutura de transporte são extremamente importantes para a ocupação dos territórios e para o crescimento econômico, entretanto a maioria dos estudiosos são categóricos em afirmar que as obras de infraestrutura de transporte isoladamente não são suficientes, sendo necessárias condições e políticas subjacentes para garantir tais resultados (HIRSCHMAN, 1961; ELBAZ-BENCHETRIT, 1997; RURAL POLICY RESEARCH INSTITUTE, 2011; NEW ZEALAND, 2014). É nesse sentido que a hipótese deste estudo foi configurada. 
Desta forma, a pesquisa tem como objetivo investigar como a infraestrutura de transporte rodoviário - implantação e manutenção/conservação das estradas de alimentação e o tronco rodoviário (BR-158) - influenciou no território da Mesorregião Nordeste de Mato Grosso a partir da década de 1940 . Os resultados apontam que as rodovias tiveram papel relevante no estabelecimento e no desfecho dos empreendimentos agropecuários familiares e latifundiários (consolidação das atividades produtivas) e subdivisões municipais.

\section{Procedimentos metodológicos}

Quanto à área de estudo, delimitou-se a Mesorregião Nordeste de Mato Grosso (Figura 1, destaque em azul). É constituída por três Microrregiões: Canarana, Médio Araguaia e Norte Araguaia, totalizando 25 municípios. A Mesorregião Nordeste de Mato Grosso possui uma área de $177.336,073 \mathrm{~km}^{2}$ e faz parte de uma das cinco mesorregiões do Estado mato-grossense: Nordeste, Norte, Sudoeste, Centro-Sul e Sudeste (Instituto Brasileiro de Geografia e Estatística, 1990a), com uma população total de 276.332 habitantes, sendo $67,77 \%$ urbana e $32,23 \%$ rural. A densidade populacional da região é de $1,5 \mathrm{hab} / \mathrm{km}^{2}$ (IBGE, 2010).

Figura 1: Localização da BR-158 e da Mesorregião Nordeste de Mato Grosso

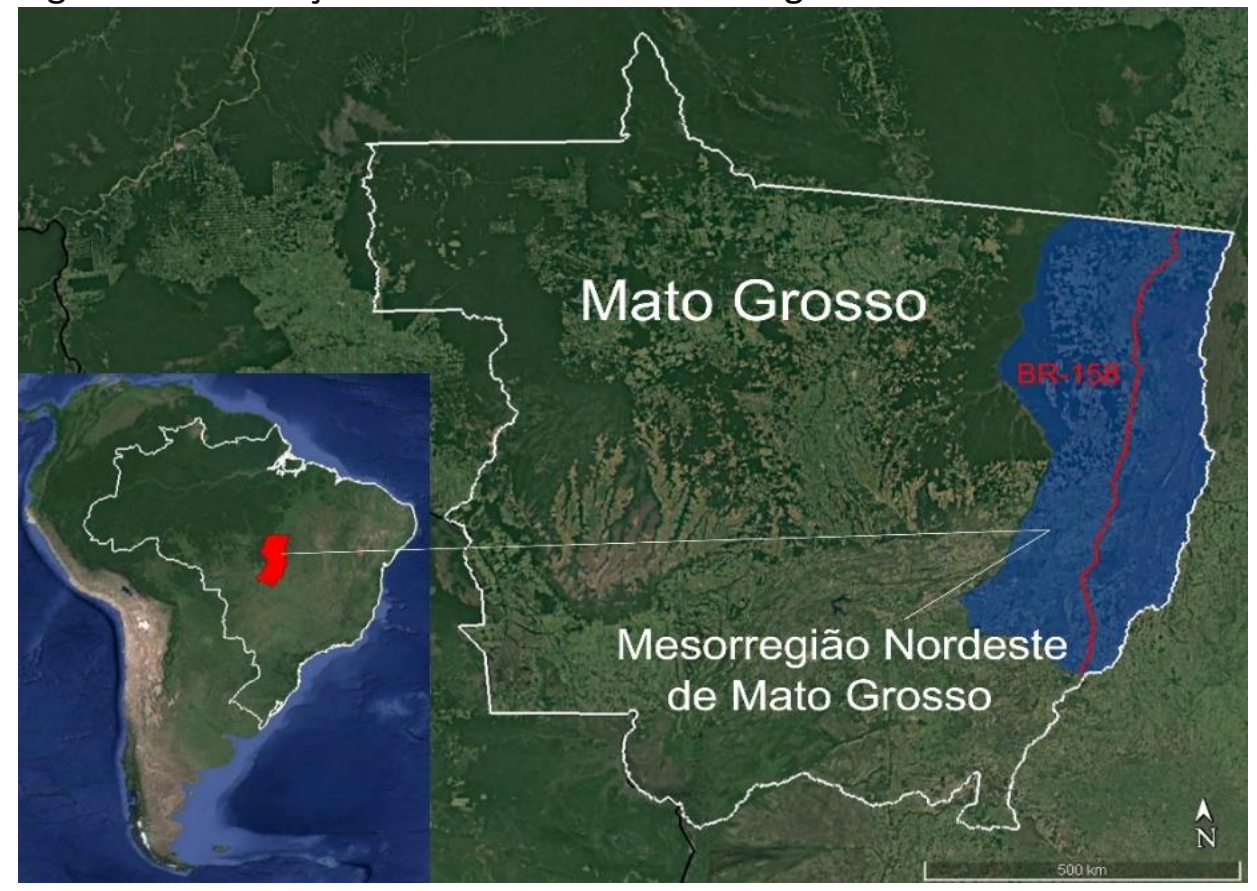

Fonte: Elaborado pelos autores, com base em arquivos $\mathrm{KML} / \mathrm{KMZ}, 2018$, manipulados por meio do software Google Earth. 
No primeiro momento do estudo foi realizado levantamento bibliográfico objetivando compreender a natureza e o contexto das imigrações na região. Na sequência, são feitas análises em um cenário posterior ao processo de colonização, com elaboração de tabelas e mapas temáticos a partir de indicadores socioeconômicos, fornecidos pelo Instituto Brasileiro de Geografia e Estatística - IBGE, especificadamente estruturação fundiária e produção agropecuária. Para tal, os municípios foram divididos em dois grupos: os "cortados pela BR-158" (12 municípios) e os "não cortados pela BR-158" (13 municípios), discriminados e detalhados na figura 2.

Figura 2: Os municípios da Mesorregião Nordeste de Mato Grosso e os grupos "cortados" e "não cortados" pela BR-158

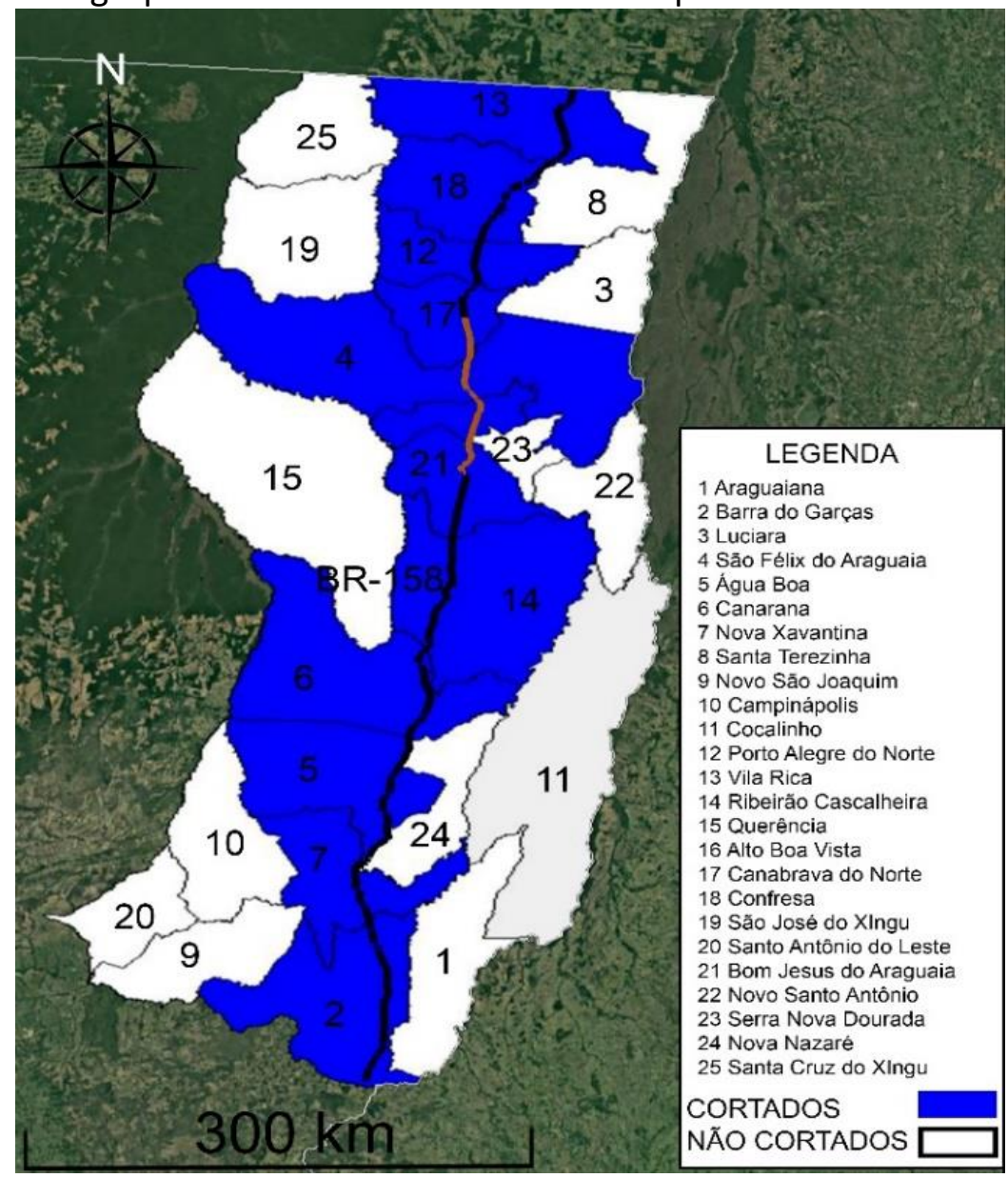

Fonte: Elaborado pelos autores, com base em arquivos KML/KMZ, 2018. Departamento Nacional de Infraestrutura de Transportes (2017), manipulados por meio do software Google Earth.

Os mapas temáticos foram elaborados a partir de dados técnicos do DNIT, dados e Séries Temporais do Instituto Brasileiro de Geografia e Estatística (IBGE), bem como arquivos livres 
KML/KMZ e tiveram relevância nesta pesquisa, por permitirem correlacionar as variáveis selecionadas entre si e em relação à distância do tronco de transporte rodoviário, a BR-158.

\section{A implantação pioneira da infraestrutura de transporte}

A Marcha para o Oeste teve início por meio da Portaria no 77, de junho de 1943, assinada pelo então Coordenador da Mobilização Econômica, órgão vinculado à Presidência da República, a qual organizava a Expedição Roncador-Xingu. Basicamente, a Expedição consistia em atravessar o Brasil de Sul a Norte, pelo centro de uma região isolada e onde havia comunidades indígenas que ainda se mantinham afastadas de todo e qualquer contato com a "população nacional". O objetivo, então, era desbravar e posteriormente colonizá-lo, levantando alicerces para futuras cidades, mediante núcleos e bases ao longo do eixo de penetração.

Dada a importância que representou a Marcha na época, o Decreto-Lei no 5.801, de 8 de setembro de 1943, considerou a Expedição Roncador-Xingu de interesse militar (BRASIL, 1943). No mesmo ano, pelo Decreto-Lei no 5.878, de 4 de outubro de 1943, a Fundação Brasil Central (FBC) foi criada para atuar na zona a ser percorrida pela Expedição, com proposito principal de vincular os objetivos da Expedição Roncador-Xingu à nova atribuição de desbravar e colonizar as regiões do Brasil Central.

Se as expedições tinham como intenção criar as vias mínimas de acesso à região para possível colonização, a FBC tinha como objetivo criar as condições mínimas para que a colonização pudesse se efetivar (VARJÃO, 1989). Assim, no período de sua existência, a FBC construiu cidades, estradas, pontes, organizou expedições ao vale do rio Xingu e Amazônia em parceria com o Serviço de Proteção aos Índios, depois com a Fundação Nacional do Índio (Funai) e Força Aérea Brasileira (FAB). Lima Filho (2000) aponta que a FBC construiu também hospitais e patrocinou várias outras atividades visando garantir condições mínimas para que a frente pioneira chegasse ao Brasil Central.

Borges (1987) explica que o trabalho da FBC se estendeu em uma área de 1,5 milhão de $\mathrm{km}^{2}$, exercido durante anos, "pacificando" metade da população das comunidades indígenas existentes no Brasil, criando postos indígenas, construindo Parques Nacionais, abrindo 3.000 quilômetros de estradas, implantando cinquenta vilas, bases e cidades.

Quanto à infraestrutura criada, é interessante observar que metade da implantação da rodovia (que posteriormente seria chamada de BR-158) foi criada pela FBC. O restante da 
implantação, foi realizado pela Superintendência de Desenvolvimento do Centro-Oeste (SUDECO) e Departamento de Estradas de Rodagem de Mato Grosso (DERMAT).

De acordo com Dunck (1997), a construção da BR-158 permitiu o avanço e a fixação de um enorme contingente de agricultores sem-terra (campesinos ${ }^{5}$, comumente chamados no Brasil de posseiros), oriundos do estado de Goiás e do sul do estado do Maranhão, que formaram povoados ao longo de sua extensão.

\section{A consolidação das atividades produtivas}

Após a "Marcha para o Oeste", os interesses econômicos se intensificaram na Mesorregião Nordeste de Mato Grosso. Programas governamentais foram criados no sentido de incentivar a consolidação populacional e o desenvolvimento de atividades produtivas. Em 1967 a FBC encerrou suas atividades, sendo substituída pela Superintendência do Desenvolvimento do Centro-Oeste - SUDECO (BORGES, 1987).

A partir da década 1960, em especial a partir de 1964, com o início dos governos militares no Brasil, surgiram planos econômicos de desenvolvimento que tinham por objetivo modernizar a agricultura do país, em especial mediante a concessão de crédito rural subsidiado pelo governo brasileiro (OLIVEIRA, 2015). Neste período, o Governo Federal criou a Superintendência para o Desenvolvimento da Amazônia (SUDAM), que em conjunto com a Superintendência para o Desenvolvimento do Centro-Oeste (SUDECO) e o Programa de Desenvolvimento dos Cerrados (POLOCENTRO), instituído em 1975 pela SUDECO, injetaram dinheiro na região mediante financiamentos e infraestrutura. Esses órgãos foram fundamentais para fomentar a criação de empresas agropecuárias e de latifúndios em Mato Grosso (NASCIMENTO, 2010). Assim, os incentivos fiscais da SUDAM se constituíram em um chamariz a novos investidores (MIGUEZ, 2001).

Segundo Marzari (2005), tais incentivos estatais tiveram impacto significativo na Mesorregião Nordeste de Mato Grosso, a qual passou a ter um acelerado processo de crescimento. Os subsídios para a região continuaram na década de 1970 e muitos empreendimentos agropecuários se instalaram na região.

\footnotetext{
${ }^{5}$ Uma das principais características do campesinato brasileiro é a não propriedade das terras ocupadas, portanto, em situação de insegurança jurídica na manutenção da posse da terra. Uma das consequências dessa falta de segurança jurídica é a grande mobilidade desse contingente populacional (DALOSTO, 2016).
} 
Azanha (2013) ressalta que a importância da BR-158 nesse processo, visto que teve a finalidade precípua de apoiar logisticamente a implantação de grandes projetos agropecuários na Amazônia Legal, com subsídios da SUDAM. Ainda, o tronco de transporte também auxiliou os projetos de colonização do Instituto Nacional de Colonização e Reforma Agrária (INCRA) colonos sulistas financiados pelo Programa de Redistribuição de Terras e de Estímulo à Agroindústria do Norte e Nordeste (PROTERRA), a partir da década de 1970.

A primeira leva de colonos sulistas se deu por volta de 1970, com a criação da Cooperativa de Colonização 31 de Março Ltda. (Coopercol). Estes primeiros colonos eram da região de Tenente Portela, estado do Rio Grande do Sul, e viviam em minifúndios ${ }^{6}$, em extrema pobreza e forte pressão ocupacional (SCHWANTES, 2008). A imigração só foi possível com o Decreto-Lei no 1.179, de 6 de julho de 1971, o qual instituiu o PROTERRA, o qual objetivava promover acesso mais fácil à terra e fomentar a agroindústria nas regiões compreendidas nas áreas de atuação da SUDAM e SUDENE.

Dessa forma, a escolha da Mesorregião Nordeste de Mato Grosso foi diretamente influenciada pelo crédito fundiário do PROTERRA, o qual contemplava a região Amazônica (acima do paralelo $16^{\circ 7}$ e à margem esquerda do Rio Araguaia). O programa financiaria a aquisição de terras por pequenos agricultores, que teriam doze anos para pagar o empréstimo, com juros de 7\% ao ano sem correção monetária. Segundo Norberto Schwantes (2008, p. 78), “era exatamente o que precisávamos", além da descoberta de "um imenso vazio demográfico, com muita terra boa e barata".

A infraestrutura de transporte criada pela FBC foi de fundamental importância na escolha da região de colonização. A região escolhida para a primeira leva de colonos distava somente trinta quilômetros da implantação da BR-158, por meio da estrada que, posteriormente, se denominou MT-326. Vale assinalar que se tratava de uma colonização essencialmente agrícola. Assim, a proximidade a um corredor de transporte era de suma importância. No documentário Pioneiros na Amazônia, de Schwantes (1980) encontra-se o seguinte relato: “A BR-158 era

\footnotetext{
${ }^{6}$ Minifúndio, nos termos do art. 4으, IV, do Estatuto da Terra (Lei federal n. 4.504/64), é todo imóvel rural de área e possibilidades inferiores às da propriedade familiar. Já a propriedade familiar, nos termos do art. 4으, II, da mesma lei, é definida como todo "imóvel rural que, direta e pessoalmente explorado pelo agricultor e sua família, Ihes absorva toda a força de trabalho, garantindo-lhes a subsistência e o progresso social e econômico, com área máxima fixada para cada região e tipo de exploração, e eventualmente, trabalhado com a ajuda de terceiros". Como se observa, o minifúndio é toda propriedade rural que não possui tamanho suficiente para que uma família possa trabalhar e conseguir o seu sustento e algum progresso (MARQUES, 2012).

${ }^{7} \mathrm{O}$ paralelo principal (linha do equador), divide a Terra horizontalmente em duas partes iguais: o hemisfério Norte e Sul. O paralelo em questão, estaria, portanto, a $16^{\circ}$ ao norte da linha do equador.
} 
absolutamente vital para o sucesso dessa colonização". Aliaram-se, então, a necessidade de emigração urgente, o acesso terrestre fornecido pela BR-158 e os requisitos legais do PROTERRA para a realização da colonização.

Standing Advisory Committee for Trunk Road Assessment (1999) aponta o efeito de "desbloqueio de locais inacessíveis" graças aos investimentos em transporte e, transpondo ao caso em estudo, a BR-158 de fato "desbloqueou" a Mesorregião Nordeste de Mato Grosso para as atividades produtivas latifundiárias e familiares. Verifica-se, também, que o avanço da estrutura logística, no caso em estudo a BR-158, foi essencial para o avanço do que Martins (1997) chama de frente pioneira, ou seja, o avanço das relações capitalistas para a região, representado pela presença de empresários, fazendeiros, do pequeno agricultor moderno. Na frente pioneira a terra passa a ser, efetivamente, mercadoria.

Após o primeiro projeto de colonização, a COOPERCOL continuou implantando projetos de colonização no mesmo molde cooperativista. O idealizador, Norberto Schwantes (2008), defendia que somente com maior produção e maior população naquela parte do Estado - até então muito pouco ocupada - seria possível fazer o governo assumir a responsabilidade pela BR158, bem como da saúde, educação, segurança pública e energia elétrica, por exemplo.

De acordo com Dunck (1997), era imprescindível a transferência de novos colonizadores. Com o sucesso do primeiro projeto de colonização, a equipe colonizadora resolveu realizar novas investidas em locais próximos ao primeiro projeto. Assim, o aumento da área colonizada visava inicialmente possibilitar o povoamento sistemático da região e, posteriormente, aumentar a produção e produtividade, além de melhorar os serviços básicos e a infraestrutura, este último pautado na conservação das estradas para o escoamento da produção e o retorno dos insumos agrícolas.

Superada a morosidade da liberação das escrituras das propriedades, a partir de 1975, iniciou-se uma nova era em todos os projetos de colonização: à medida que as escrituras públicas $^{8}$ das terras iam sendo entregues, os colonos financiavam máquinas e implementos, com garantia hipotecária, possibilitando a abertura de lavouras cada vez maiores (SCHWANTES, 2008). Augusto Dunck, um dos colonos pioneiros, relata que em 1975 iniciou-se a corrida para as compras de tratores e implementos financiados pelo Banco do Brasil, era "trator roncando por

\footnotetext{
${ }^{8}$ Nos projetos de colonização, como é o caso em análise, as terras ocupadas pelos colonos eram públicas, ou seja, pertenciam ao Estado, sendo posteriormente transferidas aos particulares. A escritura pública é o documento que comprova que houve o registro de transferência da propriedade no cartório competente.
} 
todos os lados no preparo do plantio" (DUNCK, 2014, p. 37), acompanhando o aumento exponencial da frota de tratores no Brasil (DELGADO, 1985).

Miguez (2001) explica que em 1979 o município de Barra do Garças (que na época era extremamente vasto, contemplando praticamente toda a área da Mesorregião Nordeste de Mato Grosso) constituiu-se em um dos maiores produtores de arroz de sequeiro do Brasil, com 235.832 hectares em área plantada e uma produção de 265.866 toneladas/ano. Segundo o autor, "a cidade vivia em burburinho, pegava fogo. A vinda dessas pessoas para cá, aliada à fartura de dinheiro que era distribuída [...] através de financiamentos, transformou Barra do Garças" (MIGUEZ, 2001, p. 67).

O processo de ocupação e desenvolvimento anteriormente narrado se alinha a contribuição teórica de Hirschman (1961). O economista define inicialmente a diferença entre capital fixo social (CFS) e atividades diretamente produtivas (ADP). O capital fixo social (CFS) compreende os serviços básicos sem os quais as atividades produtivas não podem funcionar, sendo, em um sentido mais amplo, todos os serviços públicos “desde a justiça e a ordem, através da educação e a saúde pública, até o transporte, comunicações, suprimento de água e de energia" (HIRSCHMAN, 1961, p. 131). O autor explica que esses serviços são básicos no sentido de permitir desenvolvimento das atividades econômicas. No mesmo viés, Elbaz-Benchetrit (1997) explica que a infraestrutura rodoviária é condição necessária, mas não suficiente para o desenvolvimento econômico, ou seja, é somente um dos fatores que favorecem o desenvolvimento econômico. Possui efeito catalisador para o desenvolvimento.

A distribuição e o financiamento de terras e maquinário pelo PROTERRA (políticas públicas subjacentes) para diversas famílias sulistas e a localização próxima à BR-158 (CFS) para o escoamento da produção permitiram e catalisaram o desenvolvimento das atividades produtivas (ADP) na Mesorregião Nordeste de Mato Grosso. Assim, entre 1972 e 1985, cerca de 1.800 famílias foram assentadas em 700.000 mil hectares na Mesorregião Nordeste de Mato Grosso pelas cooperativas de colonização COOPERCOL, CONAGRO e COOPERCANA.

De acordo com Dunck (1997), além dos projetos das colonizadoras COOPERCOL, CONAGRO e COOPERCANA, outras empresas de menor porte ou de menos atuação participaram na distribuição de terras e nos assentamentos de agricultores, quais sejam: Projeto Serra Azul, em 1978 (CODEBRASA); Projetos Noidore e Noidore I, em 1977 e 1978 (CACIQUE); Projetos Itaquerê e Itaquerê I, em 1978 (BARRAFÉRTIL); Projeto Coruá (não datado) (CODECO). 
Isto posto, o número de projetos de colonização evidenciou a atratividade que a região adquiriu, diretamente relacionada à BR-158. Tal situação corrobora com a Organização para a Cooperação e Desenvolvimento Económico (2012), ao descrever que investimento em transporte pode gerar aumento da imigração populacional e de empresas que, após o investimento na região, já não consideram o local periférico como desvantajoso. Ainda, explica que a estruturação de negócios mais "modernos" pode ser um dos resultados de novos investimentos em transporte.

Com efeito, a mecanização das lavouras no Mesorregião Nordeste de Mato Grosso foi viabilizada pela BR-158 conjuntamente aos financiamentos do PROTERRA. Entretanto, a mesma rodovia que possibilitou a implantação dos grandes projetos agropecuários e das famílias sulistas começou a se configurar em um estrangulamento da atividade agrícola que se desenvolveu rapidamente na região, ou seja, a insuficiente parcela de CFS estrangulou o desenvolvimento da parcela de ADP, atingindo, principalmente os pequenos produtores, visto que esta atividade necessita de transporte eficiente de insumos e dos grãos. Já os grandes latifundiários, respaldados fortemente pelos financiamentos da SUDAM, eram baseados em especulação e pecuária, esta última muito menos dependente de transporte.

O relato do idealizador Norberto Schwantes (2008, p. 120) esclarece a situação:

A colonização entrou num ritmo fantástico e começou a ser sentido pela população de Barra do Garças. [...]. No período da primeira grande safra, em 1977 - quando tivemos enormes problemas em nossas estradas vicinais, principalmente a BR-158, que ficou interrompida em vários trechos - passei semanas usando os helicópteros para socorrer lavouras onde, muitas vezes, agricultores desesperados precisavam apenas de uma correia para sua colheitadeira ou de outra pecinha qualquer.

Schwantes (2008, p. 120, 23) complementa:

\begin{abstract}
Naquele ano também tivemos um enorme problema com a sacaria que não chegou a tempo da colheita, porque a BR-158 estava interrompida. Muito arroz se perdeu naquele ano, por falta de infra-estrutura e houve muita revolta por parte dos associados da Coopercana, que a culpavam pelos atrasos e prejuízos que se refletiram diretamente nos pagamentos de seus débitos no Banco do Brasil. [...]. Com as chuvas, a BR-158 simplesmente ficava interrompida e não conseguíamos sensibilizar o governo estadual ou federal a intervir na reparação das pontes e balsas. Em grande parte, este serviço tinha que ser assumido pela cooperativa.
\end{abstract}

O Jornal da Terra, de 11 de março de 1978, explicita o estrangulamento vivenciado pelos agricultores familiares da Mesorregião Nordeste de Mato Grosso: 
O desabamento de um vão com menos de 10 metros da ponte sobre o Rio Areões interrompeu esta semana o tráfego na BR-158, causando incalculáveis prejuízos aos agricultores que dependem da estrada para receber o combustível usado em caminhões, colheitadeiras e secadoras. Em plena época de colheita, a falta de combustível causa grandes prejuízos a cada momento que passa, pois o arroz maduro está caindo do cacho, enquanto colheitadeiras ficam paradas. (JORNAL DA TERRA, 1978, apud SCHWANTES, 2008)

A publicação fornece mais detalhes:

Com a safra em pleno andamento - e já atrasada pelas constantes chuvas - ninguém sabia imaginar o volume das perdas com a falta de combustível para a colheita e transportes. [...] Em Canarana e Água Boa, os estoques de diesel se esgotaram em suas fazendas e mais da metade das colheitadeiras pararam. Também faltou o óleo bruto para os secadores dos armazéns e as filas para a entrega de arroz aumentaram. (JORNAL DA TERRA, 1978, apud SCHWANTES, 2008)

O documentário de Schwantes (1980) continua:

O precaríssimo estado de conservação da BR-158, totalmente abandonada pelo governo, obrigou a Copercana a intervir na solução dos graves problemas de acesso à região. Foram a Copercana e a Colonizadora, e não o governo, que apoiaram os agricultores nos transportes dos insumos e da produção através da BR, que em muitos trechos simplesmente inexistia. De nada valeram os dramáticos apelos dirigidos aos governos estadual e federal, no sentido de dotar a região de uma infraestrutura viária condizente com sua rápida expansão econômica, a fim de não desencorajar o trabalho dos pioneiros agricultores dos cerrados. A BR-158 era absolutamente vital para o sucesso dessa colonização.

Segundo Schwantes (2008), apesar da grande arrecadação aos cofres públicos do governo estadual, a pauta recente e necessária da infraestrutura de transporte levou muito tempo até ser compreendida, afetando negativamente os colonos sulistas. No estado de Mato Grosso, fortemente extrativista, os políticos mato-grossenses "desconheciam os problemas de uma ocupação agrícola, pois o garimpeiro nada reivindicava, nem o seringueiro, [...], não requerem soluções do problema de transporte, como os grãos" (SCHWANTES, 2008, p. 126), bem como a pecuária, que tem vantagens quanto à característica de deslocamento próprio.

Ainda, além da BR-158, nos períodos chuvosos, as estradas alimentadoras que faziam a ligação das produções ao tronco de transporte (BR-158) também se encontravam em péssimas condições. Dunck (1997) descreve que os trinta e cinco quilômetros da estrada alimentadora (posteriormente denominada como MT-326), que separava o núcleo de colonização de Canarana até a BR-158, ficavam completamente intransitáveis. 
De acordo com Barat (1978), as rodovias alimentadoras têm como principal função econômica ligar os troncos rodoviários às áreas produtoras. Desde que seja preservado o tráfego de forma permanente ao longo do ano, as rodovias alimentadoras possibilitam maior aproveitamento da capacidade da rede principal, aumentando o tráfego das rodovias que as compõem. No Brasil, porém, muitas áreas de elevado potencial de produção agrícola não dispõem de ligações que ofereçam condições de tráfego em todas as estações do ano, em razão da precariedade de suas características técnicas. Tais condições representam, quase sempre, fator impeditivo ao crescimento econômico e à melhoria do bem-estar social da população.

Ainda, segundo o autor, áreas carentes de rodovias alimentadoras seriam aquelas que, já possuindo uma participação percentual elevada de terras utilizadas para a cultura permanente, não têm rede complementar adequada que permita um escoamento fácil e contínuo de sua produção agrícola (BARAT, 1978). A situação vivenciada pelos colonos sulistas seria, de fato, um exemplo perfeito às palavras do economista. Schwantes (2008) registra que os prejuízos das safras de 1976, 1977, 1978 e 1979 foram enormes por falta de infraestrutura de apoio e reparo da BR-158.

Ainda, os colonos sofreram com o problema da acidez do solo, combatido com o minério calcário. A importação deste insumo de outras regiões era dificultada por conta dos altos valores de frete (precariedade da logística) e da diminuição dos financiamentos cedidos aos colonos. 0 atraso ao acesso do calcário ao final de década de 1970, nas palavras do idealizador, "levou à falência quase a metade dos agricultores [...] senti uma enorme revolta contra o governo pela sua total desatenção para com a agricultura" (SCHWANTES, 2008, p. 173). Dunck (1997) explica que os altos preços pagos pelos agricultores em relação aos fretes, a elevação do valor dos insumos (adubo, sementes selecionadas, peças de reposição dos equipamentos agrícolas) e o esgotamento do solo constituíram fortes motivos para o abandono da prática da agricultura na região.

Os projetos de colonização no final da década de 1970 começavam a ser pressionados pelos grandes empreendimentos agropecuários da região, que buscavam comprar novas áreas para a sua expansão, contando ainda com os financiamentos concedidos pela SUDAM. Os pequenos e médios produtores só conseguiram adquirir terras pelo PROTERRA até 1977. Depois disso, qualquer novo imigrante acabava se dedicando ao comércio pela impossibilidade de comprar terras diante da expansão das grandes propriedades. Tal política estimulou a concentração de terras, já que, muitas vezes, os pequenos agricultores não conseguiam 
aumentar a produção e acabavam vendendo seus lotes para os grandes proprietários (AZANHA, 2013). O relato de Dunck (1997, p. 155) esclarece a situação vivenciada pelos colonos:

\begin{abstract}
Grande parte dos produtores rurais da região tiveram seus maquinários apreendidos [...] como forma de garantir o pagamento das dívidas junto ao Banco do Brasil. Era neste momento que os agricultores vendiam as suas propriedades para novos compradores. Estes assumiam as dívidas junto às instituições bancárias (assunção de dívidas) e o restante do dinheiro da venda era repassado diretamente para o alienante [...]. Esse período de turbulência econômica vigorou por três a quatro anos. Muitos agricultores oriundos do Sul e do Sudeste foram atraídos para a região e aproveitaram a fragilidade dos colonos endividados, para adquirir terras e maquinários, por preços muito inferiores aos do mercado.
\end{abstract}

A realidade do Projeto Canarana mostrou que a modernização agrícola com máquinas e equipamentos sem um aparato institucional que viabilizasse a infraestrutura demandada no processo de produção, consumo e mercado não permitiu a sustentabilidade da atividade produtiva dos colonos. Sem conhecimento e acesso aos insumos, os reduzidos agricultores que continuaram nas terras de colonização realizaram experimentos próprios com milho, soja e arroz, nem sempre conseguindo produtividade suficiente para quitar as dívidas com o banco (RIBEIRO, 2013).

Portanto, após o final da década de 1970 - em que se iniciava a "década perdida" no Brasil e ocorria a quebra dos produtores de arroz na região em estudo -, a agricultura passou se diversificar, principalmente por meio da produção de soja, arroz, milho, seringueira e outras culturas de menor escala. A pecuária também passou a ser amplamente explorada entre os colonos e principalmente pelos grandes agropecuaristas (DUNCK, 1997).

Segundo dados do IBGE (1990b, 2015), na Mesorregião Nordeste de Mato Grosso, a área plantada de soja aumentou de 48,0\% em 1990 para 78\% em 2015 e a área plantada de arroz, que ocupava 37,0\% da área plantada em 1990, em 2015 ocupou somente 1\% da área plantada. A área total de plantio teve um aumento de $600 \%$, marcada principalmente pelo avanço da soja. Para essa análise foram consideras as culturas de soja, arroz, milho e feijão, as quais são as mais relevantes das culturas temporárias para o caso em estudo. ${ }^{9} \mathrm{~A}$ pecuária ganhou espaço. Com rebanho efetivo de 1.908.438 bovinos em 1990, em 2012 já havia 6.144.243 cabeças desse rebanho. Estabelecendo uma proporção entre cabeças de gado e população total residente, em

\footnotetext{
${ }^{9}$ Não foram encontrados dados das produções para datas anteriores a década de 1990, entretanto, é possível observar o intenso processo de substituição da produção orizícola pela sojicultora, que se iniciou em 1980 e continuou nas décadas seguintes.
} 
1990 havia aproximadamente 11 cabeças/pessoa e, em 2012, aproximadamente 23 cabeças/pessoa na Mesorregião Nordeste de Mato Grosso (IBGE, 1990b, 2012).

Segundo IBGE (1980) e IBGE (1991), entre 1980 e 1991, a população urbana e rural variou expressivamente em diversos municípios da região, conforme pode ser visto nos percentuais apresentados a seguir, sendo os primeiros relativo à população urbana e o segundo relativo às populações rurais: Água Boa, 907,1\% e 174,6\%; Barra do Garças, 42,1\% e -71,0\%; Nova Xavantina, 75,8\% e -59,5\%; Canarana, 729,8\% urbano e $-34,0 \%$.

Os dados da variação populacional acima, conjuntamente com a análise da evolução das caraterísticas agropecuárias na Mesorregião Nordeste Mato-Grossense, se alinham ao entendimento do processo de concentração fundiária na região: a falência dos colonos sulistas por motivos logísticos e técnicos e a atração de novos investimentos voltados à produção de commodities, os quais demandaram, portanto, mais tecnologia e financiamentos (menos acessível aos pequenos produtores).

Dunck (1997) argumenta que as frentes de colonização tiveram um importante papel na distribuição de lotes rurais na região, no aumento da produção e da produtividade, propiciando o aparecimento de centenas de médias propriedades agrícolas. Entretanto, reconhece que a região ainda apresenta uma grande concentração de terras, dadas as imensas propriedades agropecuárias.

O desenvolvimento das atividades produtivas e da situação fundiária dos colonos na região estudada se assemelha ao processo de caboclização ${ }^{10}$ que ocorreu com os imigrantes europeus que vieram ao Brasil durante o período imperial, conforme explicado por Linhares e Da Silva (1999). Segundo os autores, grande parte dos imigrantes que vieram para o Brasil neste período rapidamente empobrecia e pouco contribuía para a riqueza nacional. Apenas onde havia uma pronta ação do Estado, com abertura de estradas e a distribuição de terras os núcleos coloniais conseguiam se desenvolver e prosperar. Ou seja, sem o apoio estatal, no sentido de garantir uma CFS mínima, as condições para o desenvolvimento de ADP de pequenos agricultores eram, na sua maioria, inviáveis.

Isto posto, verifica-se que a estrutura fundiária construída nesse período remete ao subdesenvolvimento, na medida em que pequenos produtores familiares sulistas foram inseridos

\footnotetext{
${ }^{10}$ Caboclo, caipira ou sertanejo eram os camponeses brasileiros que não estavam integrados ao sistema de produção de exportação existente durante o período colonial e imperial do Brasil, vivendo "em torno de mínimos vitais: uma economia voltada para a produção dos gêneros necessários para o consumo e para a formação de pequenos excedentes, obtida basicamente por meio do trabalho familiar" (WISSENBACH, 1998).
} 
em um contexto com empresas capitalistas modernas, em um novo projeto de ocupação fundiária no Brasil iniciado durante o período de ditadura militar (iniciado em 1964) e que persiste até os dias atuais, pautado na produção em larga escala de commodities para exportação, incentivada pelo Estado brasileiro com vistas a garantir a entrada de divisas internacionais no país, que dependem de extensas propriedade, auxiliando no processo de concentração fundiária (DELGADO, 2005)

Esse modelo de política agrícola no Brasil prosperou, colocando o estado de Mato Grosso num expoente de produção de commodities (RIBEIRO, 2013). Os dados do IBGE (2006) verificam o processo de concentração fundiária, visto que na Mesorregião Nordeste de Mato Grosso havia apenas $8,9 \%$ do total da área cultivada na região era de agricultura familiar, sendo, portanto, 91,1\% de agricultura não familiar (IBGE, 2006).

Assim, após a consolidação da colonização sulista, em curto espaço de tempo, o vasto município de Barra do Garças apresentou uma substancial modificação no seu espaço geográfico, sendo "pontilhado" por dezenas de novas cidades (DUNCK, 1997, p. 140). Nos dados de IBGE (2018) é possível observar a intensa transformação territorial na região em estudo, pois houve emancipação, em trinta anos, de 22 municípios após o primeiro projeto de colonização realizado em 1972. Na década de 1970, houve três emancipações. Na década de 1980, foram oito e na de 1990 foram 11 emancipações.

\section{0 cenário após as frentes de colonização}

Após o processo de desbravamento da Marcha para o Oeste, a implantação de grandes latifúndios pecuaristas e, posteriormente, a colonização sulista, analisa-se o cenário das atividades produtivas distribuídas na Mesorregião Nordeste de Mato Grosso, de acordo com os grupos discriminados "cortados" e "não cortados".

Os estabelecimentos agropecuários de 5 a 10, 10 a 20, 20 a 50, 50 a 100 e 200 a 500 constituem o tipo com "área abaixo de 500 hectares" nos quais, segundo IBGE (2006), há registro de agricultura familiar no caso em estudo. Já os estabelecimentos de 500 a 1.000, 1.000 a 2.500 e acima de 2.500 hectares constituem o tipo de propriedade com "área acima de 500 hectares" nos quais, segundo IBGE (2006), não há registro de agricultura familiar no caso em estudo.

Nos municípios "cortados", os estabelecimentos agropecuários com área abaixo de 500 hectares totalizaram $81,8 \%$ do número total dos estabelecimentos agropecuários dos municípios 
selecionados e detinham $23,6 \%$ da área total ocupada por todos os estabelecimentos agropecuários dos municípios selecionados. Já nos municípios "não cortados", os estabelecimentos agropecuários com área abaixo de 500 hectares totalizaram 66,2\% do número total dos estabelecimentos agropecuários dos municípios selecionados e detinham 10,3\% da área total ocupada por todos os estabelecimentos agropecuários dos municípios selecionados. A figura 3, a seguir, ilustra a distribuição das áreas dos estabelecimentos agropecuários na Mesorregião Nordeste de Mato Grosso em 2006.

Figura 3: Quantidade total de estabelecimentos agropecuários (cor) e área ocupada pelos estabelecimentos com mais de 500 hectares (em percentual) *

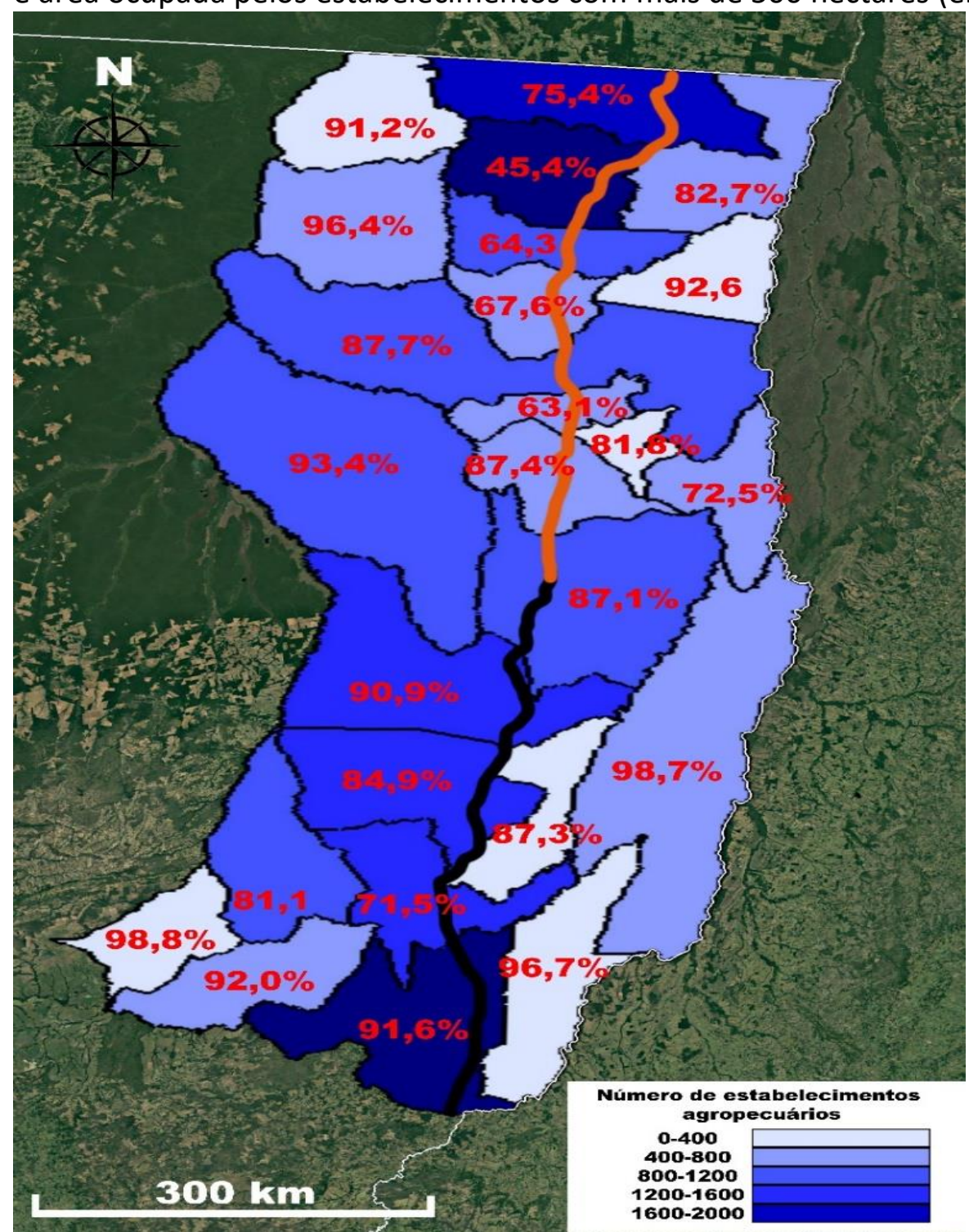

Fonte: Elaboração própria, com base em dados do IBGE (2006).

* Relativo à porcentagem do total da área ocupada pelos estabelecimentos agropecuários em cada município em 2006 
Na figura 3 é possível verificar que todos os municípios com mais de 800 estabelecimentos agropecuários foram "cortados" pela BR-158. Estes dados corroboram com Barat (1978), o qual argumenta que a ausência de rodovias alimentadoras se constitui num obstáculo maior à especialização e ao crescimento em áreas de propriedades agrícolas do tipo familiar do que em áreas onde predominam latifúndios (BARAT, 1978).

Assim, quanto mais distante da BR-158, os latifúndios estariam em situação menos desfavorável que os pequenos produtores, estes negativamente afetados tanto pela quantidade quanto pela qualidade (superfície de rolamento) das rodovias alimentadoras - fazem a ligação entre as propriedades privadas e os troncos de transporte. Essa constatação pode ser analisada observando a situação do sistema de transporte da região estudada em 2012 (Figura 4). No caso em estudo, as rodovias alimentadoras seriam basicamente as rodovias estaduais conjuntamente com algumas rodovias federais. O tronco principal é a BR-158.

Figura 4: Mapa ilustrativo da malha rodoviária estadual e federal na Mesorregião Nordeste de Mato Grosso em 2012

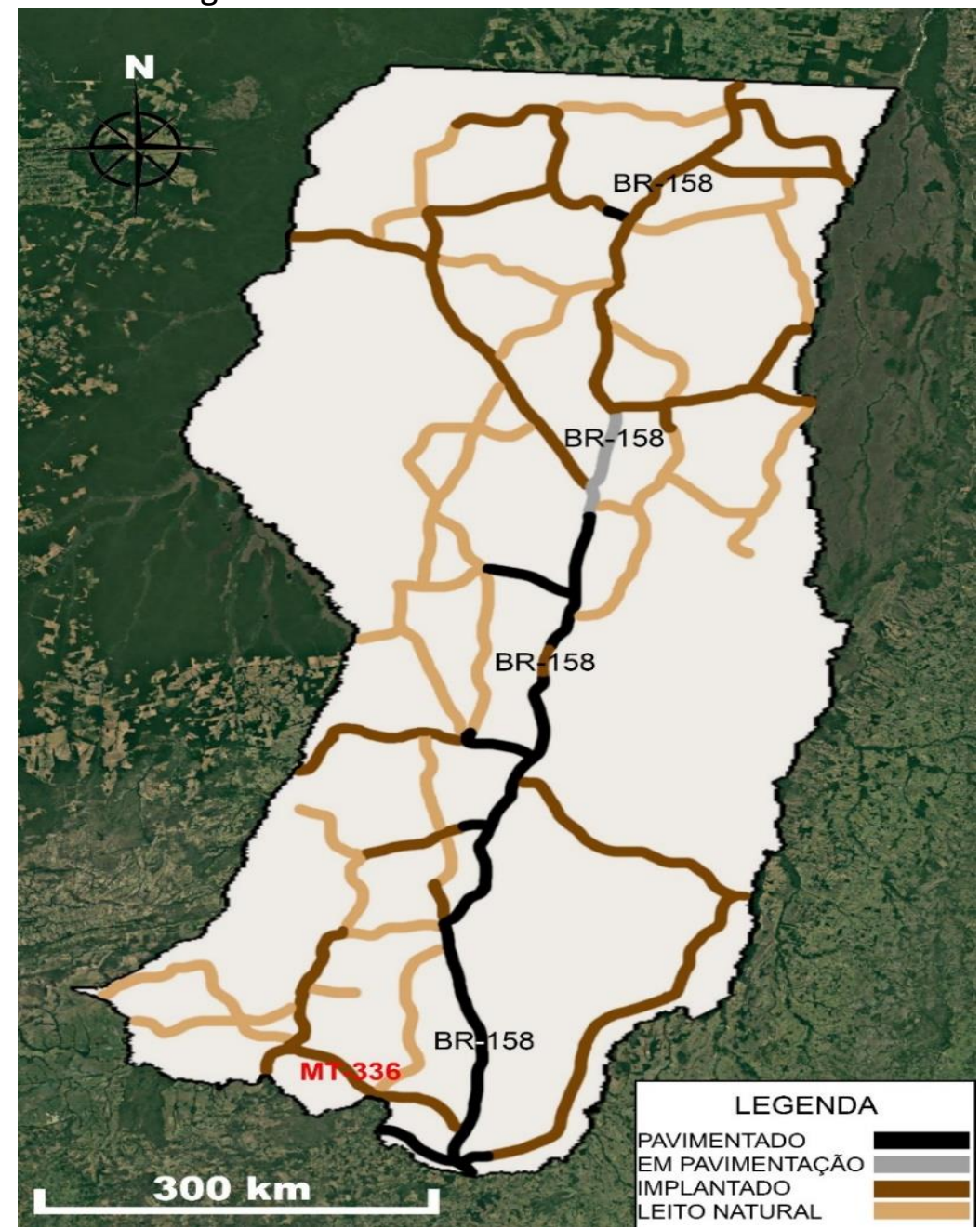

Fonte: Elaboração própria, com base em dados livres KML/KMZ, 2018, adaptado de DNIT (2012). 
As rodovias implantadas são construídas de acordo com as normas rodoviárias de projeto geométrico, enquadrando-se em determinada classe estabelecida pelo DNIT. Apresentam superfície de rolamento sem pavimentação. Essas rodovias normalmente apresentam sua superfície em revestimento primário e permitem tráfego o ano todo ${ }^{11}$ (DNIT, 2007). As rodovias pavimentadas possuem revestimento superior, ou seja, apresentam sua superfície com pavimento asfáltico, de concreto cimento ou de alvenaria poliédrica (DNIT, 2007).

Dessa forma, verifica-se que passados dez anos em referência ao censo agropecuário do IBGE de 2006, a região ainda dispunha de um sistema viário extremamente defasado. Além da própria BR-158 ainda estar em processo de pavimentação, o sistema de alimentação é basicamente constituído de rodovias implantadas e de leito natural, portanto, sem pavimentação asfáltica, salvo algumas pequenas extensões pavimentadas do sistema de alimentação.

Além da alta concentração de rodovias em leito natural - fora dos padrões geométricos e extremamente frágeis às chuvas -, as rodovias implantadas, na prática, são constantemente negligenciadas, visto que necessitam de manutenção e conservação constante do poder estatal. É o caso da rodovia MT-336 (Figura 4). O estudo de caso realizado em 2014 por Dalosto, Colturato e Pasqualetto (2016), no que diz respeito à real situação da rodovia, conclui que, mesmo sendo classificada como implantada pelo DNIT - possuindo, teoricamente, boa trafegabilidade durante todos os períodos do ano -, a MT-336 encontrava-se em uma situação de extrema precariedade, em virtude, principalmente, da negligência do poder estadual quanto à manutenção e conservação da rodovia (DALOSTO et al, 2016).

Mesmo sendo um estudo aplicado a um caso específico dentro da malha rodoviária alimentadora da região estudada, não seria presunção transpor esse cenário local ao cenário geral, visto que se trata de problema logístico da região que é reconhecido pela população e, também, amplamente divulgado na mídia, sendo sistematicamente alvo de reivindicações dos produtores e moradores. O paralelo se fortalece na medida em que o sistema de rodovias alimentadoras está praticamente todo sob a responsabilidade do Estado de Mato Grosso. Assim, a Figura 3-maiores subdivisões municipais próximas ao traçado e menor concentração fundiária próximas ao traçado - evidencia que o distanciamento do tronco principal de transporte,

\footnotetext{
${ }^{11}$ Entretanto, mesmo se a geometria e a granulometria da pista forem satisfatórias (tratamento primário), se não houver práticas rotineiras de manutenção e conservação, principalmente do sistema de drenagem, a pista rapidamente perderá sua trafegabilidade (IPT, 1988).
} 
conjuntamente com diminuição da qualidade das rodovias de alimentação acarretam um ambiente mais desfavorável à novos investimentos, às pequenas propriedade rurais e, em consequência, gerando concentração fundiária.

Para fortalecer o paralelo entre o tronco de transporte e as transformações geoeconômicas na região em estudo, foram analisadas a produção agropecuária: grãos selecionados (maior pertinência) e rebanho de bovinos. Os municípios "cortados pela BR-158" possuíam 1.211.974 hectares de área plantada dos grãos selecionados, constituindo, assim, $55,9 \%$ do total da área plantada para os grãos selecionados na Mesorregião Nordeste de Mato Grosso. Da mesma forma, os treze municípios não cortados pela BR-158 somaram 956.192 hectares de área plantada para os grãos selecionados, contemplando, portanto, $44,1 \%$ do total da área plantada para os grãos selecionados na Mesorregião Nordeste de Mato Grosso (IBGE, 2015). A partir dos dados apresentados, verifica-se que a proporção aproximada entre a área plantada dos grãos selecionados entre os municípios "cortados" e "não cortados" pela BR-158 é de $1,4: 1$, respectivamente.

Quanto ao rebanho efetivo de bovinos, registrou-se 3.524 .036 bovinos nos municípios “cortados pela BR-158", constituindo, desse modo, 60,5\% do total de bovinos na Mesorregião Nordeste de Mato Grosso. Já os treze municípios “não cortados pela BR-158” somaram 2.303.785 bovinos, contemplando, assim, 39,5\% do total (IBGE, 2015). Como se observa, a proporção aproximada o rebanho efetivo de bovinos nos municípios cortados e não cortados é de 1,5:1, respectivamente. Estes dados mostram que nas regiões mais próximas ao traçado da BR-158 há maior produção das lavouras temporárias selecionadas e maior número de bovinos.

\section{Considerações finais}

A primeira intervenção experimentada pela região em estudo, a "Marcha para o Oeste", foi iniciada com a Expedição Roncador Xingu e chancelada com a atuação da Fundação Brasil Central. A FBC instaurou o CSF básico - ordem (presença do estado), educação (escolas), saúde pública (hospitais), transporte (estradas e pistas de pouso) - e, dessa forma, viabilizou o início da consolidação das atividades produtivas (ADP) básicas, visto que, a partir desse período, iniciouse de fato o avanço produção agropecuária na região, a qual, então, ganhou atratividade a novos investimentos. 
Somadas a atuação da Expedição Roncador-Xingu e a da FBC, foi implantada uma extensa rede estradas de penetração e de aproximadamente 460 quilômetros de implantação (melhores características geométricas e geotécnicas) da BR-158. Isso permitiu o avanço e a fixação de posseiros, oriundos de Goiás e do Sul do Maranhão, formando povoados ao longo de sua extensão.

Todo esse processo evidenciado entre a atuação da Marcha para o Oeste e o período de vultosos incentivos da SUDAM já fornece indícios da influência que a BR-158 teve na estruturação da Mesorregião Nordeste de Mato Grosso, visto que a implantação da rodovia incentivou a imigração e a consolidação populacional próxima ao traçado da rodovia, bem como viabilizou a instalação dos grandes empreendimentos. A rede de transporte desempenhou seu caráter permissivo.

Ainda, a infraestrutura de transporte criada pela FBC foi de fundamental importância na escolha da região de colonização dos sulistas, visto que vários projetos de colonização foram executados próximos ao traçado da BR-158. Esses projetos de colonização particular eram baseados essencialmente na produção agrícola e, portanto, necessitavam de um corredor de transporte para o escoamento da produção. Entretanto, com o aumento da produção agropecuária na região, a BR-158 não suportou a intensificação do fluxo de escoamento da produção e do transporte de insumos básicos, o que evidencia que, conforme Hirschman (1961), a parcela de CFS não acompanhou o aumento de ADP e tal fato começou a se configurar em um estrangulamento da atividade produtiva.

O estrangulamento logístico atingiu principalmente os pequenos produtores familiares, pois estes dependiam muito da BR-158 para escoamento de suas produções e para a importação de insumos agrícolas. Além do problema da falta de infraestrutura viária adequada, durante a década de 80 do século passado, o aumento da inflação, o corte dos financiamentos e a falta de apoio técnico e logístico, prejudicaram em demasia os projetos de colonização, ocasionando a falência de diversos pequenos produtores rurais e, em razão de dívidas ou pela impossibilidade de uma produção lucrativa, houve um processo de concentração fundiária.

Novamente, esse processo reforça a retórica bibliográfica da temática, visto que houve políticas subjacentes (PROTERRA) para incentivar as atividades produtivas, entretanto faltou infraestrutura de transporte para viabilizá-las, evidenciado seu caráter indispensável. Em outras palavras, a infraestrutura de transporte rodoviária não atuou em seu caráter permissivo. 
As fortes imigrações, o vertiginoso aumento da produção orizícola, bem como sua intensa substituição pela sojicultura e o aumento da produção pecuarista, o êxodo rural e as subdivisões do vasto território do município de Barra do Garças em vários municípios, principalmente próximos ao traçado da BR-158, fornecem dados que corroboram com a hipótese do estudo.

A confirmação da hipótese se fortalece com a análise do cenário após o processo de colonização, no qual os municípios "cortados pela BR-158" concentraram maior número de estabelecimentos agropecuários, tiveram maior produção dos grãos selecionado, evidenciando a atração de investimento advindos da proximidade com o tronco de transporte.

Ainda, as análises revelam que o pequeno produtor rural é mais afetado pela falta de capital social fixo (CSF) e pela falta de políticas públicas voltadas ao setor, em especial a falta de financiamento subsidiado, acarretando na inviabilização da produção em escala comercial. Essa situação ficou evidente no caso em estudo, no qual houveram diversas políticas públicas para a atração de produtores rurais para a região que, após a descontinuidade das políticas públicas direcionadas ao setor, acabaram não conseguindo manter-se economicamente, acarretando na "falência" de diversos produtores e um processo de concentração fundiária em razão da necessidade de venda das terras para o pagamento das dívidas bancárias.

\section{Referências}

AZANHA, G. Estudos etnoecológicos dos impactos nas Tls Parabubu-Culuene, Areões, Pimentel Barbosa e Marechal Rondon. Componente Indígena do Processo de Licenciamento da EF 354, 2013. https://www.academia.edu/27927588/Os Xavante a ferrovia EF 354?auto=download. Acesso em: 25/11/2016.

BARAT, J. A evolução dos transportes no Brasil. Rio de Janeiro: IBGE; IPEA, 1978.

BORGES, D. R. Rio Araguaia: corpo e alma. São Paulo: Ibrasa, 1987.

BRASIL. Missão Rondon: apontamentos sobre os trabalhos realizados pela Comissão de Linhas Telegráficas Estratégicas de Mato Grosso ao Amazonas, sob a direção do Coronel de Engenharia Cândido Mariano da Silva Rondon, de 1907 a 1915. Brasília: Senado Federal, 2003.

DALOSTO, C. D. Políticas Públicas e os direitos quilombolas no brasil: o exemplo Kalunga. Rio de Janeiro: Lumen Juris, 2016.

DALOSTO, J. A. D.; COLTURATO, S. C. O.; PASQUALETTO, A. Estradas Vicinais de Terra: estudo técnico da rodovia MT-336. Enciclopédia Biosfera, v. 13, n. 23, p. 1637-1648, jun. 2016.

Disponível em:

http://www.conhecer.org.br/enciclop/2016a/engenharias/Estradas\%20vicinais.pdf. Acesso em: 25/11/2016.

BRASIL. Decreto n. 5.878, de 4 de outubro de 1943. Considera de interesse militar a Expedição Roncador-Xingu, 1943. Disponível em: 
http://legis.senado.gov.br/legislacao/ListaPublicacoes.action?id=32686. Acesso em: 25/11/2016.

BRASIL. Decreto-Lei no 1.179, de 6 de julho de 1971. Institui o Programa de Redistribuição de Terras e de Estímulo à Agro-indústria do Norte e do Nordeste (PROTERRA), altera a legislação do imposto de renda relativa a incentivos fiscais e dá outras providências, 1971a. Disponível em: http://www.planalto.gov.br/ccivil 03/decreto-lei/1965-1988/Del1179.htm. Acesso em: $11 / 01 / 2018$.

DELGADO, G. C. Capital Financeiro e Agricultura no Brasil. São Paulo: Ícone; UNICAMP, 1985.

DELGADO, G. C. A questão agrária no Brasil: 1950-2003. In: JACCOUD, L. Questão social e políticas sociais no Brasil contemporâneo. 2. ed. Brasília: IPEA, 2005. p. 51-90.

DNIT. Mapa Multimodal, 2012.

http://www.mt.gov.br/documents/363190/2303883/MAPA RODOVIARIO 2012.pdf/71d4c9e8b9cb-4581-8fd6-12ec7761195a. Acesso em: 11/01/2018.

DNIT. Terminologias rodoviárias usualmente utilizadas, 2007.

http://www.dnit.gov.br/download/rodovias/rodovias-federais/terminologias-

rodoviarias/terminologias-rodoviarias-versao-11.1.pdf.

DNIT. Dados fornecidos pelo engenheiro Otto Zittlau, 2017.

DUNCK, E. M. S. Canarana: um projeto de colonização cooperativista. 1997. Dissertação

(Mestrado em Direito Agrário). Universidade Federal de Goiás, Goiânia, 1997.

DUNCK, A. Diamantes. Canarana: Cegraf, 2014.

ELBAZ-BENCHETRIT, V. Autoroutes: impacts sur l'économie et l'environnement. Paris: Presse de I'Ecole Nationale des Pontes er Chaussees, 1997.

HIRSCHMAN, A. O. Estratégia do desenvolvimento econômico. Rio de Janeiro: Fundo de Cultura S.A., 1961.

IBGE. Censo Demográfico. Rio de Janeiro: IBGE, 2010. Disponível em:

https://sidra.ibge.gov.br/pesquisa/censo-demografico/demografico-2010/inicial. Acesso em: 11/01/2018.

IBGE. Divisão Regional do Brasil em Mesorregiões e Microrregiões Geográficas. Rio de Janeiro: IBGE, 1990a.

IBGE. Pesquisa Pecuária Municipal. Rio de Janeiro: IBGE, 1990b. Disponível em:

https://sidra.ibge.gov.br/pesquisa/ppm/quadros/brasil/2016. Acesso em: 11/01/2018.

IBGE. Censo Demográfico. Rio de Janeiro: IBGE, 1991. Disponível em:

https://sidra.ibge.gov.br/pesquisa/censo-demografico/demografico-2010/inicial. Acesso em: 11/01/2018.

IBGE. Censo Agropecuário. Rio de Janeiro: IBGE, 2006. Disponível em:

https://sidra.ibge.gov.br/pesquisa/censo-agropecuario/censo-agropecuario-2006/segundaapuracao. Acesso em: 11/01/2018.

IBGE. Censo Demográfico. Rio de Janeiro: IBGE, 2010. Disponível em: https://sidra.ibge.gov.br/pesquisa/censo-demografico/demografico-2010/inicial. Acesso em: 11/01/2018. 
IBGE. Produção Agrícola Municipal. Rio de Janeiro: IBGE, 2015. Disponível em: https://sidra.ibge.gov.br/pesquisa/pam/tabelas. Acesso em: 11/01/2018.

IBGE. Cidades. Rio de Janeiro: IBGE, 2018. Disponível em: https://cidades.ibge.gov.br/. Acesso em: $11 / 01 / 2018$.

INSTITUTO DE PESQUISAS TECNOLÓGICAS. Estradas vicinais de terra: manual técnico para conservação e recuperação. Brasília: IPT, 1988.

LIMA FILHO, M. F. Aragarças: a cidade encantada no sertão de Goiás. Horizontes Antropológicos, Porto Alegre, n. 13, p. 65-87, 2000.

LINHARES, M. Y; SILVA, F. C. T. Terra prometida: uma história da questão agrária no Brasil. Rio de Janeiro: Campus, 1999.

MARQUES, B. F. Direito Agrário Brasileiro. 10. ed. São Paulo: Atlas, 2012.

MARTINS, J. S. Fronteira: a degradação do Outro nos confins do humano. São Paulo: Hucitec, 1997.

MARZARI, M. R. Memória de migrantes: onde viver o fazer faz o saber. Barra do Garças: Cathedral, 2005.

MIGUEZ, J. M. G. Causas do Araguaia. Goiânia: Kelps, 2001.

NASCIMENTO, A. M. Barra do Garças, das pedras aos Grãos: uma história de migrações e ocupações (1960-1980). 2010 Dissertação (Mestrado em História). Pontifícia Universidade Católica de Goiás, Goiânia, 2010.

NEW ZEALAND. Contribution of transport to economic development: International literature review with New Zealand perspectives, 2014.

http://www.transport.govt.nz/assets/Uploads/Our-Work/Documents/edt-contribution-oftransport-lit-review.pdf. Acesso em: 11/01/2018.

OLIVEIRA, C. L. F. A construção histórica do agronegócio e a questão agrária. Revista de Direito Agrário e Agroambiental, v. 1, n. 1, p. 20-35, set. 2015.

NASCIMENTO, A. M. Barra do Garças, das pedras aos Grãos: uma história de migrações e ocupações (1960-1980). 2010. Dissertação (Mestrado em História). Pontifícia Universidade Católica de Goiás, Goiânia, 2010.

RIBEIRO, A. R. A colonização promovida por empresas e famílias do Centro-Sul do Brasil na Amazônia Mato-Grossense. 2013. (Doutorado em Desenvolvimento Sustentável do Trópico Úmido). Núcleo de Altos Estudos Amazônicos, Universidade Federal do Pará, Belém, 2013.

RURAL POLICY RESEARCH INSTITUTE. Rethinking Federal Investments in Rural Transportation: Rural Considerations Regarding Reauthorization of the Surface Transportation Act. 2011. http://www.rupri.org/Forms/RUPRI Transportation April2011.pdf.

SCHWANTES, N. (Produtor). (1980). Pioneiros na Amazônia [DVD] Produção: Norberto Schwantes. [s.l.]

SCHWANTES, N. Uma cruz em Terra Nova. Brasília: Edição do Autor, 2008.

STANDING ADVISORY COMMITTEE FOR TRUNK ROAD ASSESSMENT. Transport and the economy: full report, 1999.

http://webarchive.nationalarchives.gov.uk/20050301192906/http:/dft.gov.uk/stellent/groups/ dft econappr/documents/pdf/dft econappr pdf 022512.pdf. Acesso em: 11/01/2018. 
VARJÃO, V. Aragarças: portal da Marcha para o Oeste. Brasília: Senado Federal, 1989.

WISSENBACH, M. C. C. Da escravidão à liberdade: dimensão de uma privacidade possível. In: F. A. Novais; N. Sevcenko. História da vida privada no Brasil: República: da Belle Époque à Era do Rádio. 2. ed. São Paulo: Companhia das Letras, 1998, p. 49-130. 